\title{
Conclusion: international education programs and round table
}

\author{
Y.L. Orlov ${ }^{1,2 *}$, A.N. Savostyanov ${ }^{1,2,3}$, T.G. Amstislavskaya ${ }^{2,3}$, L.I. Aftanas ${ }^{2,3}$ \\ ${ }^{1}$ Institute of Cytology and Genetics SB RAS, Novosibirsk, Russia \\ ${ }^{2}$ Novosibirsk State University, Novosibirsk, Russia \\ ${ }^{3}$ Scientific Research Institute of Physiology and Basic Medicine, Novosibirsk, Russia \\ *e-mail:orlov@bionet.nsc.ru
}

Key words: integrative bioinformatics, education, databases, international science exchanges

The round table on education and integration of bioinformatics data together with science cooperation will conclude the First Sino-Russian Workshop on Integrative Bioinformatics and Systems Biology. Russian and international experts in the field of bioinformatics, education programs and neurobiology from top world universities will discuss education programs. Science groups from China by Prof Xiaodong Zhao (Shanghai Jiao Tong University), Prof Ming Chen (Zhejiang University), and Prof HongYu Zhang (Huazhong Agricultural University) will discuss integration of bioinformatics data and education programs. Prof M.Chen will present professional initiatives in bioinformatics in China, work of Zhejiang Bioinformatics Society.

Dr. Fyodor Kondrashov, Institute of Science and Technology, Klosterneuburg, Austria will tell about experience in organization of Young Scientists Schools on bioinformatics in Russia. The invited speakers from Russia will continue the discussion about national programs in fundamental medicine - presented by Irina M. Larina, Institute of Mathematical Problems of Biology RAS, Alexey A. Lagunin, Russian National Research Medical University named after N.I. Pirogov, Maria G. Samsonova, Saint-Petersburg Polytechnic University.

Dr Olga F. Krebs (Heidelberg Institute for Theoretical Research, Heidelberg, Germany) and Dr Maxim V. Zakharsev (Norwegian University of Natural Sciences, Oslo) will give a talk about integration of data in bioinformatics and open source platforms on computer biology in Europe. Prof Ralf Hofestädt (Bielefeld University, Germany) will discuss German-Chinese network on bioinformatics and education. Dr Marko Djordjevic (Belgrade University, Serbia) will tell about the integrating computational systems biology in research and education. Prof Tatiana Tatarinova (University of La Verne, USA) will give the educational program review "Bioinformatics: science of a toolbox?" The neurobiology experts from Academia Sinica, Taiwan ROC - Arthur C. Tsai, Hung-Ming Chang, Ya-Ling Yang - will share their expertise in research.

Bioinformatics, as an interdisciplinary field, is a case example for analysis of science history perspectives. During the seminar the analytical materials on increasing the effectiveness of the implementation of the activities of the roadmap projects of the National Technological Initiative in Russia will be discussed. We aim to develop methodological recommendations on educational projects including the usage in educational process based on the example of the Department of Medicine and Psychology and the Humanitarian Institute of Novosibirsk State University.

Acknowledgements: The participation of the incited speakers at the BGRS conference and the workshop has been supported by Russian Ministry of Science project 28.12487.2018/12.1. 